\title{
CONTRIBUIÇÕES A UM PENSAR SOCIOLÓGICO SOBRE A DEFICIÊNCIA
}

\author{
Gustavo Martins Piccolo* \\ EnICÉIA GonÇALVES MENDES*
}

\begin{abstract}
RESUMO: O artigo, erigido mediante processo de revisão literária, objetiva apresentar as contribuições do grupo londrino denominado Disability Studies, arcabouço teórico pouco conhecido em terras brasileiras e cujos textos possibilitam uma transformação nuclear na maneira de interpretar a deficiência, ao abordá-la como produto da insensibilidade da sociedade capitalista em incorporar as diferenças nas suas mais distintas esferas, portanto, obra de complexa discriminação institucional para a qual a única resposta apropriada é a ação revolucionária sobre a estrutura que nos circunscreve.
\end{abstract}

Palavras-chave: Educação especial. Sociologia. Deficiência.

\section{Contributions to a SOCIOLOGICAL THINKING ABOUT DISABILITY}

ABSTRACT: The article, built through a process of literature review, aims to present the contributions of the London group called Disability Studies, whose theoretical framework is practically unknown in Brazilian territory and whose texts allow a nuclear transformation in the way disability is interpreted, by conceiving it as the product of the capitalist society's insensitivity to incorporate the differences - in all their distinct spheres -, therefore being the work of complex institutional discrimination towards which, the only adequate response is the revolutionary action upon the very structure that circumscribes us.

Key words: Special education. Sociology. Disabilities.

\footnotetext{
* Doutor em Educação Especial pela Universidade Federal de São Carlos (Ufscar). E-mail: gupiccolo@yahoo.com.br

* Doutora em Psicologia e professora adjunta da Universidade Federal de São Carlos (Ufscar). E-mail: egmendes@ufscar.br
} 


\title{
Contributions À unE RÉFLEXION SOCIOLOGIQUe SUR LE HANDICAP
}

\begin{abstract}
RÉSUMÉ: L'article a été élaboré à partir d'une révision littéraire, il se propose de présenter les contributions du groupe londonien appelé Disability Studies, une source théorique peu connue dans des terres brésiliennes et dont les textes rendent possible une transformation nucléaire dans la manière d'interpréter le handicap pour l'expliquer comme étant le produit de l'insensibilité de la société capitaliste à intégrer les différences dans leurs plus distinctes sphères, donc, une œuvre de complexe discrimination institutionnelle pour laquelle la seule réponse appropriée est l'action révolutionnaire sur la structure qui nous entoure.
\end{abstract}

Mots-clés: Éducation spéciale. Sociologie. Handicap.

\section{Introdução}

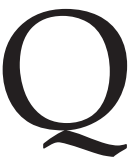

uanto mais avançou o capitalismo e mais elevado se mostrou seu desenvolvimento, mais individualizado se tornou o homem, trazendo consigo novas dificuldades de ordem e controle social em sua composição. Entre este conjunto de problemas, o corpo aparece como portador de novas variáveis, sendo dividido não apenas entre ricos ou pobres, alimentados ou subnutridos, submissos ou indolentes, fortes ou fracos, como observamos em estádios históricos anteriores. Passa a ser também definido entre mais ou menos utilizável, mais ou menos favorável ao investimento rentável, aqueles com perspectivas de maior ou menor grau de sobrevivência e, claro, os que se mostram mais ou menos proveitosos para receber o novo treinamento e disciplina necessários à produção gestada pela máquina.

Se em praticamente todo o período feudal as pessoas com corpos disformes se adaptaram à atividade laboriosa sem grandes dificuldades, devido ao caráter rudimentar do labor ali materializado, o mesmo não se pode dizer quando do aparecimento e posterior consolidação do regime capitalista, o qual tem transformado as diferenças em desigualdades intrínsecas.

Na senda destes elementos, a tese nuclear defendida pelos Disability Studies - teóricos do modelo social (grupo londrino composto por Oliver, Barnes, Abberley, Barton, Shakespeare e Finkelstein, todos ativistas da Union Physical Impairment Against Segregation (Upias), com limitações físicas patentes e que içaram a temática da deficiência a uma questão de direitos, se valendo da contribuição de outras minorias sociais e levando-a para o interior do Departamento de Sociologia da Leeds University) - é a de que um corpo com lesões não estaria apto ao regime de exploração da força de trabalho alavancado pelo capitalismo devido à radicalidade que a norma ostenta na assunção destas atividades. O padrão emergente do sujeito ideal ao modelo capitalista, o ser que se encaixa à máquina, exige um tipo de corpo no 
qual a força e a destreza física se mostram fatores fundamentais, elementos estes que excluem de suas relações diretas significativa parcela das pessoas com deficiência.

Evidente que tal comentário não pode ser visto como forma de grandezas absolutas. É um aporte em níveis de tendência. Marx (1996) já afirmava de maneira enfática que o capitalismo também se apropriou dos corpos em dissonância às normas instituídas. Nesse interstício, eram oferecidos os piores salários e postos para os mesmos no intuito único de amplificar o lucro total, processo que, longe de amenizar a opressão sofrida por estes sujeitos, torna ainda mais repugnante tal prática.

Ainda sob esses lineamentos, não é escusado lembrar que na década de 20 do século passado Henry Ford estabeleceu taxas fixas de remuneração para pessoas com deficiência em suas fábricas automotivas. Nas palavras de Ford (apud GLEESON, 1999, p. 27-28),

[...] se mostra totalmente desnecessária a exclusão dos deficientes das fábricas, embora a imensa maioria destas tenham assim procedido há mais de um século. Expulsam a torto e direito os deficientes dos ramos de trabalho. Quanta imbecilidade e falta de visão sobre o futuro. Mal imaginam que esta atitude intempestiva e de uma ignorância econômica atroz fomenta fenômenos como a mendicância. Penso totalmente diferente. Os deficientes devem ser empregues nas fábricas, tornando a caridade desnecessária, visto que aqueles que antes pareciam incapazes de ganhar a própria vida e eram retirados das classes produtivas passam novamente a ocupar lugar neste ambiente. Como fazer isso? Simples. Em todo processo produtivo existem funções em que o trabalhador não precisa de muita mobilidade para realizar. Algumas delas, aliás, exigem um comportamento estático sob risco de perda da vida ou de membros. Limpeza e desobstrução das máquinas e caldeiras é apenas um destes exemplos. Estas funções podem perfeitamente ser desenvolvidas pelos deficientes. Minhas fábricas já estão a adotar este sistema. Todas possuem uma grande quantidade de deficientes para executar aquelas operações consideradas como de alto risco. Olhem a vantagem deste engenho. Se colabora com a redução desta peste social, que é a mendicância, e ainda se contrata o trabalhador a um preço muito abaixo do que aquele que pagaríamos para um homem sadio. E os deficientes não têm o porquê reclamar. De expulsos a empregados com baixos salários é um avanço significativo. Ajudamos a sociedade e nos ajudamos. Pena que não tenha percebido isto antes. Teria feito mais lucro e dado menos dinheiro nas portas das igrejas e nas esquinas das ruas.

Sob este aspecto, o capitalismo não tem preconceito algum quando o assunto reside em objetivar mais lucro e universalizar o processo de retirada da mais valia. Ninguém escapa de seus tentáculos. Contudo, importa neste momento destacar o quão cruel foi e tem sido este modus econômico no sentido de englobar a força de trabalho expressa pelas pessoas com deficiência, estejamos falando em sua exclusão destes postos ou em sua inclusão pelas margens. Pela complexidade que envolve este ordenamento, os teóricos do modelo social preferem utilizar o termo "opressão" (e não exclusão) para se referir à insensibilidade do atual sistema perante suas diferenças. No entender de Abberley (1987, p. 163), 
A alegação de que as pessoas com deficiência são oprimidas envolve, no entanto, a compreensão de um amplo número de fatores. A nível empírico significa argumentar que as pessoas com deficiência podem ser consideradas como um grupo cujos membros estão em um posição inferior aos demais membros da sociedade porque são pessoas com deficiência. Significa também argumentar que essas desvantagens estão dialeticamente relacionadas à ideologia ou grupo de ideologias que justificam e perpetuam tal situação. Além disso, também compreende a alegação de que as desvantagens e as suas ideologias de apoio não são naturais, tampouco inevitáveis. Finalmente, implica a identificação de alguns beneficiários para este estado de coisas.

Por conseguinte, as iníquas formas de opressão vivida pelas pessoas com deficiência nas sociedades modernas nada possuem de natural, tampouco devem ser vistas como um acidente ocorrido na consolidação do sistema capitalista. Fazem parte de sua estrutura, são endêmicos tal como suas crises, a exploração do trabalhador e sua condição miserável, o desmatamento irresponsável e ingovernável da natureza, a necessidade de desemprego e da constituição de um exército industrial de reserva não incorporada à produção, a fim de facilitar a manutenção dos baixos salários e das condições degradantes de trabalho. Trata-se de um fenômeno histórico gestado por determinada organização produtiva.

Destarte, a representação figuracional que se fez e ainda se faz destes sujeitos como essencialmente dependentes, limitados, passivos e carentes em medidas assistencialistas não condiz com a realidade, posto demarcar um ardil que toma por objetivo obnubilar a estrutura sinistra do sistema que nos circunscreve. É a perversidade do capitalismo que assim os amolda e rotula. Portanto, tais sentenças conformam um mecanismo de inversão do real materializado pela produção de ideias, representações e conceitos extremamente violentos, mas que se portam como benignos e donos de uma benesse nuclear. $\mathrm{O}$ maior exemplo destas práticas hodiernas pode ser encontrado na própria noção de assistencialismo.

Visto como uma proteção natural à dependência que marca a deficiência, o assistencialismo acaba por revigorar o domínio daqueles definidos como normativos em comparação aos que se desviam da norma, justificando o perfilhar de mecanismos diretos (cujo maior exemplo pode ser sintetizado no processo de institucionalização, ainda hoje atuante) ou indiretos (tais quais os mecanismos criados para a dispensa das relações laboriosas ao invés da obrigatoriedade de transformação de dito espaço) que os segreguem do restante da sociedade. Estas inversões profundamente autoritárias são das mais cruéis e devastadoras que um grupo pode sofrer, ao ver tornada suas diferenças em assimetrias explícitas, as quais criam, reforçam e popularizam a relação mando-obediência entre um ser supostamente superior e outro inferior. Sob tal escopo, eivado de lineamentos biológicos e jus naturalizantes, a deficiência tende a ser localizada como pertencente ao indivíduo, sua propriedade, falha e limitação orgânica, obra de uma natureza incompleta que atesta a necessidade de 
seu sujeito aceitar de pronto e de maneira mansa e humilde toda sorte de firmamentos médicos edificados sobre seu corpo. Não é de estranhar que para Zola (1989, p. 28), na modernidade, "os médicos se transformam em verdadeiros senhores do destino das pessoas com deficiência. Definem as limitações e possibilidades, o proibido e permitido, roubando-lhas a própria autoria da vida e o sentido da mais bela paráfrase marxiana: a de que os homens fazem sua história". Mas será que apenas podemos explicar a deficiência por firmamentos médicos e biológicos? Pode a citada área locupletar todas as formas de entendimento e relações que perpassam o fenômeno? Materializam a essência ou apenas a aparência de uma das múltiplas formas de existir no mundo? Não será esta composição anistórica uma forma de proteção sub-reptícia às iniquidades que pululam sob os meandros do capital, afinal, sob tal lógica quem deve mudar são as pessoas e não a sociedade, a qual é responsabilizada, no máximo, para a construção de instituições específicas que pouco impacto desempenham sobre a estrutura organizativa do capital?

Tais questionamentos se mantiveram às sombras da academia até os estertores do século $X X$, quando em seu último quartil começam a ser criticados de forma visceral, ao menos no que se refere a naturalidade da discriminação sobre o deficiente. Não nos surpreende, portanto, que mesmo em áreas como a Sociologia, epistemologicamente interessada na produção simbólica e material dos conflitos sociais, ecoassem e ainda ecoem vozes quase uníssonas de um discurso composto por falas teoricamente alheias à constituição histórica da aludida condição, reiterando a posição tomada por Oliver (1996) de que, ao longo de décadas e mais décadas, a deficiência foi tratada como um tema pré-sociológico por grande parte das ciências humanas e sociais, tornando-se uma problemática apenas quando a medicina a havia anteriormente diagnosticado e esquadrinhado. Portanto, fazia-se, quando muito, uma sociologia colonizada pelos parâmetros do biológico. Este, no entender de Oliver (1990), é um dado objetivo e visível ao primeiro olhar de qualquer pesquisador que tenha na deficiência seu tema central, para nos valermos de uma das assertivas mais comentadas de Marx e Engels (1984, p. 86-87), "um pressuposto real de que só se pode extrair na imaginação, portanto, constatável por via puramente empírica".

Caso se desejasse falar sociologicamente sobre a deficiência, era necessário desbravar o campo, tendo em mente que, mais do que receber a descrição do fenômeno, se faz candente concebê-lo, catalisar seu processo de aparecimento histórico. Este novo entendimento estaria por nascer. Desde o alicerce, tudo estava ainda por se construir.

Partindo deste suposto, Oliver (1996) realiza um extenso estudo sobre as áreas responsáveis pela produção acadêmica que tinham a deficiência como objeto de estudo, em todo o Reino Unido, e acaba por constatar que quase tudo o que adentrava a academia sobre a aludida temática se mostrava como oriundo de lineamentos 
analíticos médicos e biológicos. No mais, apenas retratos de vida ou autobiografias que se mostravam precários no sentido de entender a realidade que ali se desdobrava. Como conclusão, enfatizou existir uma necessidade urgente de que outras disciplinas como a Sociologia, Antropologia, História e Pedagogia tomassem para seu escopo analítico a análise da deficiência, na medida em que o perfilhar de um determinado fenômeno sobre outras bases também é considerado um novo entendimento do mesmo.

Como consequência, é preciso assumir o risco de partir de uma natureza diferente, de pensarmos de forma negativa quanto a está lógica maculada pela miopia do cotidiano. Se a lógica biológica da interpretação da deficiência se ancorou sobre o apagar de sua historicidade, a nossa deve se amoldar antiteticamente, impregnando-a da mesma e explicando seus complexos a partir de um intricado processo de relação com a sociedade. A guisa destes elementos, Oliver (1990, p. 28) assevera em tons ressonantes: "(...) é chegada a hora de investigarmos sociologicamente a deficiência. Esta é uma revolução teórica que para os deficientes significará um segundo maio de 68, cuja consecução foi denominada por nós de modelo social da deficiência". Entretanto, antes de destacarmos os principais elementos deste novo campo cognoscitivo, nominado Disability Studies, uma pergunta se faz essencial: Será mesmo que a situação tracejada por Oliver (1990) e corroborada por Abberley (1987) sobre a quase inexistência de estudos sociológicos sobre a deficiência também se reflete em terras brasileiras?

\section{Contextualizando nosso espaço}

Objetivando responder ao questionamento anterior e na busca de contribuições analíticas materializadas pela Sociologia sobre o fenômeno da deficiência, arquitetamos uma espécie de estado da arte das dissertações e teses na citada área. Além de mapear o que está sendo produzido sobre a temática, o complexo edificado poderia nos fornecer indicativos concretos no que tange a contributos para a construção de uma teoria social da deficiência.

Para a realização de tal empreitada acessamos inicialmente a página da Coordenação de Aperfeiçoamento de Pessoal de Nível Superior (Capes: http://www. capes.gov.br/cursos-recomendados), a fim de que pudéssemos elencar os cursos de mestrado e doutorado em Sociologia/Ciências Sociais devidamente reconhecidos pelo órgão diretivo. Feito isto, visitamos o sítio de cada um dos programas que disponibilizam sua produção de forma digital, com o intuito de levantar suas respectivas produções de 1990-2010, época em que, em função de documentos como a Declaração de Salamanca e a de Jontiem, a temática da deficiência aflora em distintas localidades. 
A quantidade de dados levantados é imensa, projeção essa facilmente hipotetizada. Contudo, nossa intenção quando da realização de tal tarefa estava em identificar apenas as produções que tinham a deficiência como problemática central a estes estudos. Para tanto, mediante inserção nos tópicos "Pesquisas/procuras refinadas/avançadas", fornecidos pelos próprios programas de pós-graduação, buscamos inventariar os trabalhos que contivessem as palavras deficiência e sociologia concomitantemente em algum campo de busca (processo concretizado pela utilização da valência booleana deficiência/deficiente and sociologia), quaisquer que fosse ele: título, resumo, palavras-chave. Selecionados os trabalhos que versavam sobre a temática deste estudo, os mesmos foram lidos na íntegra, atentando para qualquer referência que fizessem aos Disability Studies, na medida em que esta corrente teórica se configura, no entender de Giddens (2007), como aquilo que de mais desenvolvido foi escrito sobre a deficiência. Este processo teve duração de quatro meses, de março a junho de 2011, e os resultados são expressos no Quadro 1, na página seguinte.

O conjunto de dez trabalhos - entre dissertações e teses - encontrados nos Programas de Pós-Graduação em Sociologia traça a sombria perspectiva do quanto a deficiência se compõe como um tema solenemente ignorado pelo campo. Dos dez trabalhos publicados, apenas um, o de Geraldi (2010), se remete a literatura erigida pelos Disability Studies, e, mesmo assim, por módicas três páginas. Quanto aos outros 5.681 títulos publicados na área da Sociologia, existe alguma probabilidade de os mesmos terem se valido desta literatura? Ousamos afirmar a quase total impossibilidade desta hipótese, pois se os trabalhos que versam sobre a deficiência desconhecem a aludida literatura, conforme nossos dados atestam, o que pronunciar sobre aqueles que se desenvolvem na investigação de outras categorias e que sequer tomam tal tema como problemático?

É como se a Sociologia ainda não tivesse descoberto a opressão gestada pela deficiência, tal qual percebe com o racismo, o sexismo e as fobias sexuais e étnicas. Qual a razão em se ignorar uma parcela tão volumosa e massivamente oprimida da população? A resposta é mais simples do que se possa imaginar. A deficiência é vista essencialmente pelos sociólogos como tema autoexplicativo e consolidado, cuja base se dá na senda de lineamentos estranhos a seu corpus teórico. Ora, para quê explicar algo já explicado?

Dita composição não fica restrita apenas ao ambiente da Sociologia. A Educação Especial experimenta, via de regra, relações sinonímicas; não pensa a deficiência, embora seja seu tema dileto, partindo de um suposto já dado. Prova disso é que no Programa de Pós-Graduação em Educação Especial (PGEES), da Universidade Federal de São Carlos (Ufscar) - único programa específico de Educação Especial no Brasil e fundado no longínquo 1978 -, trabalho algum busca consolidar uma relação constitutiva entre Sociologia e deficiência, tampouco se nota qualquer diálogo 
(seja no resumo, título ou palavras-chave) quanto aos autores dos Disability Studies nas 242 produções analisadas também no período de 1990-2010, compostas por 170 dissertações e 72 teses, dado este que confirma o ostracismo que citado corpo teórico goza no seio das academias brasileiras.

\section{Quadro 1}

Dissertações e teses consultadas em programas de Sociologia (PPGS)/Ciências Sociais (PPGCS)

\begin{tabular}{|c|c|c|c|c|}
\hline $\begin{array}{l}\text { Instituição de Ensino } \\
\text { Superior (IES) }\end{array}$ & $\begin{array}{l}\text { Títulos totais } \\
\text { pesquisados }\end{array}$ & Mestrado & Doutorado & $\begin{array}{c}\text { Versam sobre a } \\
\text { deficiência }\end{array}$ \\
\hline UFBA (PPGCS) & 181 & 181 & - & - \\
\hline UFES (PPGCS) & 2 & 2 & - & - \\
\hline UFMA (PPGCS) & 68 & 68 & - & - \\
\hline UFJF (PPGCS) & 13 & 13 & - & - \\
\hline PUC/MG (PPGCS) & 150 & 144 & 6 & 3 (Dissertações) \\
\hline UFPA (PPGCS) & 86 & 67 & 19 & 1 (Dissertação) \\
\hline UFCG (PPGCS) & 236 & 223 & 13 & - \\
\hline UEL (PPGCS) & 56 & 56 & - & 1 (Dissertação) \\
\hline UERJ (PPGCS) & 359 & 246 & 113 & - \\
\hline PUC/RJ (PPGCS) & 33 & 33 & - & - \\
\hline UFRN (PPGCS) & 140 & 100 & 40 & - \\
\hline UFSM (PPGCS) & 13 & 13 & - & - \\
\hline UFPEL (PPGCS) & 40 & 40 & - & - \\
\hline PUC/RS (PPGCS) & 69 & 55 & 14 & 1 (Dissertação) \\
\hline UNISINOS (PPGCS) & 30 & 30 & - & - \\
\hline UNICAMP (PPGCS) & 348 & - & 348 & - \\
\hline UNESP/MAR (PPGCS) & 101 & 78 & 33 & - \\
\hline UFRRJ (PPGCS) & 171 & 140 & 31 & - \\
\hline UFAL (PPGS) & 22 & 22 & - & - \\
\hline UFC/CE (PPGS) & 436 & 280 & 156 & - \\
\hline UNB (PPGS) & 532 & 300 & 232 & 1 (Tese) \\
\hline UFG (PPGS) & 63 & 50 & 13 & - \\
\hline UFRGS (PPGS) & 330 & 243 & 87 & - \\
\hline UFSCar (PPGS) & 52 & 39 & 13 & 1 (Dissertação) \\
\hline USP (PPGS) & 787 & 300 & 487 & - \\
\hline
\end{tabular}




\begin{tabular}{ccccc} 
UNICAMP (PPGS) & 178 & 120 & 58 & - \\
UNESP/ARA (PPGS) & 248 & 178 & 70 & 1 (Dissertação) \\
UFRJ (PPGS) & 476 & 353 & 123 & - \\
UENF (PPGS) & 8 & 8 & - & - \\
UFSC (PPGS) & 368 & 303 & 65 & - \\
UFPR (PPGS) & 58 & 40 & 18 & 1 (Dissertação) \\
UERJ (PPGS) & 37 & 30 & 7 & - \\
$\begin{array}{c}\text { Total 32 (IES) } \\
(64 \%)\end{array}$ & $5691(100 \%)$ & 3745 & 1946 & $10(0,18 \%)$ \\
$(96,8 \%)$ & $(34,2 \%)$ & 1 Dissertações + \\
\hline
\end{tabular}

Evidente que estes dados, por si só, não justificam a necessidade de apropriação de tal literatura, tampouco sua apresentação em um artigo. Nem todo ineditismo denota uma ruptura de paradigmas. Contudo, este não nos parece ser o caso da literatura perfilhada pelos Disability Studies. Não é apenas Giddens (2007), um dos mais eminentes sociólogos britânicos, que assevera a importância de a Sociologia se apropriar destes textos. Inclusive o mesmo, na $6^{\mathrm{a}}$ edição de seu livro Sociology rebatiza o capítulo, antes intitulado "Health, Illness and Aging", por "Health, Illness and Disability", tendo um subcapítulo intitulado "The Sociology of Disability", no qual apresenta os pressupostos orientadores do modelo social da deficiência.

Zola (1989, p. 33), seguramente um dos maiores pensadores sobre a deficiência nos Estados Unidos, destaca em balanço de 30 anos de intenso ativismo que o modelo social foi o que mais ofereceu contributo para a constituição de um novo significado sobre a deficiência. Em suas palavras, "Sua influência e radicalidade são tamanhas que sequer podemos falar em uma prática de ressignificação, é construção de algo novo, o significado e sentido de deficiência, criação esta ancorada na base de um corte radical sobre o saber anteriormente construído".

Nos estertores do século XX, notamos a criação na Espanha da Asociación Espanhola de Sociología de la Discapacidad (Asesdis), a qual traduz como principal empreitada a "[...] aprendizaje de las relaciones establecidas por los teóricos del modelo social, el proceso de traducir las ideas en otro contexto, el español, y la tarea de contribuir para el enriquecimiento y la expansión de este modelo" (Asesdis, 2002, p. 3). Jenny Morris (2001, p. 28), uma das feministas mais importantes na atualidade, destaca claramente que, "com acertos e equívocos, indubitavelmente, os Disability Studies se compõem como a única literatura sociológica de fato e direito na explicação da deficiência, promovendo uma verdadeira revolução em sua forma de entendimento e luta política". 
A força da citada literatura também invade terras francesas, de modo que Stiker (2006, p. 187) aponta que “[...] certamente uma das principais agendas no campo da Educação Especial consista em se apropriar dos Disability Studies e ir além das posições ali colocadas como ponto de partida de uma revolução no entendimento da deficiência". Ora, por todos esses apontamentos, parece diáfano que a literatura perfilhada pelos teóricos do modelo social alcançou repercussão internacional e engendra novidades ao campo, pressuposto que, coadunado a total ausência desta literatura em terras brasileiras, demarca a necessidade imperiosa na tradução destas ideias.

\section{Apresentando os Disability Studies}

Indubitavelmente, o surgimento e desenvolvimento da literatura produzida pelos Disability Studies estão ligados ao aparecimento dos chamados movimentos ativistas que borbulharam no pós-maio de 1968, ainda que sua consolidação date efetivamente da década de 1990. De acordo com Barton e Oliver (1997), até o início da década de 70 do findado século a tendência da moda estava expressa na resignação social das pessoas com deficiência e na luta pelo aumento de medidas assistencialistas para as mesmas, elementos estes que sobredificultavam qualquer espécie de visualização de um movimento político com vistas à transformação social.

Porém, tal disposição não tardou em ser alterada. O maio de 1968, ou melhor, os maios de 68, pois foram vários na extensão da Europa - interseccionados pelo incremento de lutas democráticas estabelecidas pelas então chamadas minorias sociais (SARTRE, 1978) -, não passaram despercebidos pelos incipientes movimentos de pessoas com deficiência na América do Norte, Inglaterra e em toda a Europa mediterrânea, os quais viam nas lutas dos negros, mulheres e homossexuais em direção à aquisição de direitos supostamente inalienáveis uma espécie de espelho que refletia passos a serem seguidos. Assim, as conquistas de um grupo minoritário foram corretamente interpretadas como potentes molas propulsoras para conquistas similares de outros grupos, dando quórum à ideia de Sartre (1978) de que tudo o que é humano me interessa e que a luta de uma minoria por seus direitos produz resultados positivos em outros grupos.

Tão logo da dissipação simbólica e cultural deste período absolutamente fervilhante, tornou-se notório que os movimentos de pessoas com deficiência deveriam imperiosamente reorganizar a forma como esta era interpretada pelas múltiplas literaturas que versavam sobre o tema. Para tanto, como primeira tarefa de sua agenda reivindicaram o direito de serem atores de sua própria história, de uma forma que transcendesse as tão habituais escritas autobiográficas sobre a hercúlea tarefa de superação da deficiência, posto estas reiterarem sobremaneira a teoria da deficiência 
como tragédia pessoal. Ora, se a deficiência é vista como uma forma de tragédia pessoal, tal significação tem implicações concretas nos serviços destinados e na maneira como nos relacionamos com ela. Entre outras coisas, como tragédia, tal qual uma enchente, um terremoto, um tornado, se justificam medidas de corte caritativo e assistencial, tornando a temática mais uma questão de boa vontade que um problema político.

Em segundo lugar, se assim o é, não podemos medir esforços para que a mesma possa ser evitada; prevenção que se dá nos ambientes de trabalho, na alimentação, lazer, entre outros. Terceiro, se a deficiência é uma tragédia e mesmo com todas as tentativas de se evitá-la ela se faz presente, torna-se imprescindível a criação de mecanismos e ferramentas para que a mesma seja tratada e curada, objetivando sanar o problema. O papel de protagonista do saber médico e de seu corpo de profissionais salta aos olhos. Se a cura não é possível, deve-se remediar tal condição mediante estratégias de reabilitação para que tais pessoas funcionem de forma mais similar possível àquelas definidas como normais.

Em síntese, no quadro da deficiência como tragédia pessoal, a mesma é, na melhor das hipóteses, tolerada. Evidente que não pretendemos sugerir que a prevenção, a cura, a reabilitação e o acompanhamento médico sejam em si elementos maléficos, o que seria um total descalabro. Mas eles representam uma imagem incompleta da questão, são parte e não o todo. Em virtude destes elementos, era preciso criar uma literatura sobre bases distintas e com objetivos voltados para as esferas de atuação política. Sob estes questionamentos abrolham os chamados Disability Rigths Movement em diversas localidades do globo, adquirindo destaque - pela forma de atuação e contestações promovidas - a britânica Union Physical Impairment Against Segregation (Upias) e a norte-americana Independent Living Movement (ILM), ambas coordenadas por pessoas com deficiência.

E é da Upias que abrolham os principais anseios e personagens daquilo que viria a ser batizado como modelo social da deficiência. Nascida em 1975, a Upias tem como principal manuscrito a obra intitulada Princípios fundamentais da deficiência, a qual, logo em sua primeira página, destaca o propósito de sua fundação. Para a Upias (1976, p. 4-5), as pessoas com deficiência

Já sabem muito bem o que é se sentir pobre, isolado, separado, discriminado, marginalizado e oprimido melhor do que qualquer especialista poderia julgar. Vivemos na carne essa experiência todos os santos dias de nossa existência. Nós, como União que somos, não estamos minimamente interessados em discussões sobre como é terrível ser desativado. O que interessa neste momento é projetarmos formas para alterar nossa condição de vida e assim superar as deficiências impostas sobre nossa desorganização anátomo-fisiológica por uma sociedade que está altamente organizada para nos excluir. Em nossa opinião é somente o prejuízo real que temos que aceitar, a citar, algumas limitações funcionais que exercem um inegável efeito em nossas vidas. Nada mais do que 
isso. Todos os problemas adicionais e totalmente desnecessários advindos pela forma como somos tratados, e acreditem estes são os elementos fundamentais de nossa exclusão e não os primeiros, precisam ser superados e não aceitos.

Sob essa bandeira se arquitetará os primevos anseios dos teóricos do modelo social. Por conseguinte, os Disability Studies objetivam chamar a atenção para as tendências de desativação presentes nas estruturas da sociedade moderna e configurar mecanismos que possam gestar políticas, teorias e práticas que confrontem tal situação. Compõem, assim, uma arquitetura que destaca como os rótulos pejorativos sobre a deficiência são criados e historicamente impostos, portanto, não eleitos, os quais, apesar de não corresponderem à realidade, moldam uma feição social politicamente divisionista, que tantos agravos tem causado àqueles submetidos a tal prática de etiquetagem.

Romper com essa tradição é um compromisso firmado pelo citado grupo, assim como a afirmação taxativa do significado da deficiência, das atitudes assumidas sobre a mesma e da noção de incapacidade como uma construção cultural e situacional orientada para interesses escusos permeados por uma sociedade somática, alienada e alienante. Sob este novo lineamento se rejeita organicamente as categorias de explicação normativas ou qualquer outra forma de construção social divorciada da experiência direta das pessoas com deficiência. $\mathrm{O}$ argumento crucial neste solo histórico é o de que

\footnotetext{
Todas as pessoas com deficiência experimentam múltiplas maneiras de restrições sociais, seja devido à inacessibilidade de alguns ambientes ou de noções questionáveis de inteligência e competência social, da inabilidade de a população em geral se comunicar mediante uma linguagem gestual ou pelo uso do Braille, ou ainda pelas atitudes de descrédito e preconceito desferidas contra as pessoas com deficiência. (OLIVER, 1996, p. 44)
}

O passo fundante rumo à consecução de uma nova proposição analítica foi tracejado ao se edificar a distinção pioneira entre lesão e deficiência, tornada pedra angular do movimento. A primeira é vista como a falta de parte ou da totalidade de um membro, órgão ou sentido não funcional. Portanto, refere-se às condições biofísicas do indivíduo, em clara alusão ao referencial médico, ao passo que a deficiência trata-se da "desvantagem ou restrição de atividade causada por uma organização social contemporânea que não leva em conta as diferenças expressas por pessoas com deficiências, excluindo-as da participação nas atividades sociais" (Upias, 1976, p. 14). Sobre esta distinção, se constrói o conceito central pelo qual todas as produções posteriores dos Disability Studies irão se reportar, qual seja: “a deficiência é algo imposto, sob a base de nossas lesões, pela maneira como somos desnecessariamente asilados e excluídos da plena participação na sociedade" (idem, ibid., p. 3-4). Exemplar manifesta-se a definição prática e concreta feita por Morris (2001, p. 25), para quem 
[...] a deficiência não é um produto de falhas individuais, mas um fenômeno socialmente criado, por isso, as explicações para a mudança de seu caráter opressivo devem ser buscadas na transformação da sociedade. A distinção feita pela Upias, excelente por sinal, entre deficiência e lesão pode se retratada com um exemplo modular. A incapacidade de andar representa uma lesão, enquanto que a incapacidade de entrar em um edifício, pois a entrada apenas pode ser realizada por um lance de degraus, é uma deficiência. Definição lacônica, mas extremamente efetiva para um repensar do fenômeno abordado.

Nessa arquitetura teórica passa a ser perfeitamente compreensível a pessoa ter uma lesão e não experimentar a deficiência, cuja consecução depende do grau de flexibilidade da sociedade em se adaptar as mais diversas diferenças. Cria-se, assim, um novo conceito de deficiência que tem por peculiaridade ser tanto nativo como analítico. Analítico porque permite a análise de um determinado conjunto de fenômenos, neste caso a deficiência, e apenas faz sentido no corpo de uma dada teoria, ancorada na necessidade em se trazer a sociologia para a explicação da deficiência. Nativo por ser uma categoria que surge da própria vivência do grupo em questão. É a experiência da deficiência que passa a ser vista como ponte de corte da definição da mesma. Portanto, tal conceito também adquire um sentido prático, efetivo, histórico, objetivo e específico para determinado grupo humano.

O conceito criado pelo modelo social parte da ideia de que um fato social, a deficiência, apenas poderia ser explicado por outro fato social (uma noção de claro verniz durkheimiano): a opressiva sociedade capitalista. Com isso, objetiva-se criar um conceito sociológico para a deficiência que pudesse substituir o anterior, de base biológica. Essa forma ontológica de investigação abrolha em um contexto histórico no qual os acadêmicos negros buscavam criar um novo conceito para raça e explicar a discriminação como produto social e não derivada de qualquer composição biológica. As semelhanças são evidentes e contributivas a ambos os movimentos.

Tal como o conceito sociológico de raça é diametralmente distinto daquele definido pela biologia, a deficiência conceituada pelo modelo social é radicalmente díspar daquela definida pelo modelo individual. Tanto uma quanto outra são vistas, desde então, em termos de opressão social por uma sociedade insensível as diferenças. Contudo, a interseccionalidade com os estudos sobre raça não se constitui como a evidência mais explícita da ligação dos estudos sobre deficiência com outros grupos minoritários.

Ora, a distinção entre lesão e deficiência materializada nos escritos da Upias e tomada como pedra angular dos Disability Studies, embora não confessada, se constitui como um claro paralelo em relação aos estudos de gênero, o qual enfatiza o caráter fundamentalmente social das divisões baseadas no sexo e destaca que imbricadas às diferenças biológicas existentes entre mulheres e homens estão outras de ordem social e culturalmente construídas. Na esteira destas análises, os estudos 
sobre a deficiência enfatizam que, com base na lesão, outras diferenças são construídas e atravancam as possibilidades de inserção ao coletivo, acabando por gestar o fenômeno da opressão. É a esta (a opressão) que se dá o nome de deficiência, a qual não possui estrita relação com a lesão, mas, sim, com a organização perfilhada pelo modus operandi capitalista.

Tal como o sexo não explicaria a opressão sofrida pelas mulheres na sociedade, cuja concreticidade deveria ser buscada na estruturação patriarcal da mesma, o corpo com lesão não determinaria o fenômeno sócio-político-cultural de subalternidade experimentado por seus sujeitos. Explanar a condição de opressão impressa sobre os deficientes em razão de perdas de habilidades provocadas pela lesão ou qualquer desorganização biológica era confundir lesão e deficiência, tal como sexo e gênero.

Assim como o papel de gênero que cabe a cada sexo é fruto de um longo processo de socialização, a transformação do significado da lesão em deficiência também perfaz uma via estritamente social. Nada há de natural nela, aliás, nada do que é essencialmente humano o é.

Os humanos não são naturais por sua natureza. Não andamos naturalmente sobre as patas traseiras, sendo que enfermidades como pés planos, dores nas costas e as populares hérnias nos testemunham empiricamente e de forma carnal que o corpo ainda não se adaptou por completo à estrutura bípede e a postura ereta. Isto prova que até nossas características genéticas e hereditárias são históricas, fruto do domínio do homem sobre a natureza e não do desígnio biológico ou divino. O homem se faz homem por meio de um salto ontológico para fora da natureza, somos o que nos temos feito e, certamente, continuaremos fazendo enquanto existirmos. Tudo o que é natural deve ser situado, contextualizado, uma vez que a naturalização do social representa uma tentativa de inversão da empiria dos fatos como forma de justificar um determinado saber-poder, que tem a função latente de manutenção do staus quo e do domínio ideológico exercido sobre as minorias despossuídas quanto aos aportes tidos como ideais.

Esta situação é colocada às claras pelo modelo social, que, ao situar a deficiência para além da ideia de um problema trágico de ocorrência isolada de alguns indivíduos menos afortunados, para os quais a única resposta apropriada seria o tratamento médico em direção à visualização da deficiência como uma situação de discriminação institucional coletiva - e para esta a única resposta apropriada é a ação política -, inverte radicalmente os vetores que perfilhavam seu entendimento na sociedade (OLIVER, 1990).

Se é a sociedade que incapacita as pessoas com deficiência, a única forma de estas alterarem tal situação é mediante intensas lutas para transformar o estado 
atual de forças e assumirem o controle sobre suas próprias vidas. O novo universo gestado pelo modelo social opõe ao discurso colonizador expresso pelo saber normativo, médico, clínico e reabilitador uma práxis crítica, sociológica, política, inclusiva e contextualizada, gestando, quando interiorizada conscientemente, uma nova forma de pensar. E quando pensamos diferentes já não somos os mesmos. É claro que o surgimento de um novo homem apenas se materializará de fato com o abrolhar de uma nova sociedade. Contudo, e isto é de fundamental importância, apenas quando as pessoas com deficiência forem capazes de indicar o caminho para o qual concorre objetivamente a dialética de seu desenvolvimento é que poderão despertar para a consciência do próprio processo, e isto implica uma suspensão de tudo o que foi anteriormente dito e feito sobre ser deficiente na sociedade. Somente então a deficiência poderá surgir como categoria derivada da história e seu consequente desmantelar como pressuposto derivado da própria práxis que altera nuclearmente a estrutura social. Este é o desejo inaudito do modelo social.

A criação deste novo mundo não é denominada de socialismo, comunismo ou por qualquer terminologia antecipada. Cabe aos homens definir seus destinos e o nome que darão a realidades distintas. A necessidade premente está em superar o capitalismo e construir uma realidade sobre outras bases. Claro que a criação de um novo mundo será um árduo e difícil processo sujeito a quedas, derrocadas e novas quedas. Entretanto, o levantar sempre se faz necessário. A grandeza de um homem não se mede pela quantidade de quedas que sofre durante sua vida, mas, sim, por quantas vezes ele se levanta perante as mesmas e as sucumbe ao terreno do passado.

É preciso olhar em frente, para frente. Muitos chamarão isto de utopia. Mas, como bem assinalou Oscar Wilde (1996, p. 90), "um mapa do mundo que não visualiza alguma forma de utopia não merece ser visto. A humanidade está sempre em processo de desembarque e ancoragem em novas terras. Terras que não estão dadas e precisam ser cultivadas, semeadas também de sonho". Destarte, a utopia da qual falamos deve ser vista como futuro objetivado, esteja ele ancorado em uma temporalidade ao alcance de nossas mãos ou posterior a nossa existência. A luta do homem como gênero jamais sucumbe com o final das individualidades, destino de todos.

Destarte, é fundamental nos despirmos da ideia sobejamente conhecida de que a realização de um ideal revolucionário não pode ser postergada para além da vida daquele que prescreve o mesmo. Não podemos ser tão egoístas e querer que tudo se resolva em nosso tempo. O tempo de uma vida humana é dramaticamente escasso, este é o inelutável absoluto da condição humana. Ninguém transcende a morte. Entretanto, nem só de presente vive o homem. Acreditar que o mundo será outro e instituído sobre distintas bases após nossa morte não pode ser visto como 
credo religioso ou uma espécie de crença na vida após a morte. A história social e a esperança na humanidade nos levam a confiar neste caminho e, por conseguinte, cedo ou tarde, continuamos a acreditar no aparecimento de uma nova sociedade que rompa com todo o lineamento da anterior e possa de fato se denominar como democrática.

Mesmo porque, como assevera Oliver (1990), apenas uma sociedade efetivamente democrática guardará um conceito libertário de deficiência, uma vez que na produção da própria vida os homens contraem relações determinadas, necessárias e independentes de sua vontade, relações que correspondem a uma determinada etapa do desenvolvimento das forças produtivas materiais. No capitalismo, tais relações jamais concretizarão o anseio emancipatório em sua plenitude e a possibilidade máxima de liberdade, pressupondo, assim, uma total transvolaração dos valores, uma nova antropologia, um tipo humano que rejeite os princípios performáticos estruturantes das sociedades estabelecidas, livre da agressividade e brutalidade características de nosso tempo.

A simplicidade propositiva edificada pelos teóricos do modelo social choca qualquer sabedoria convencional sobre a deficiência, em um primeiro momento. Mas também é uma de suas funções. Chocar, ruir certezas, abalar convicções. Isto é profundamente libertador, uma vez que inverte paradigmas anteriormente consolidados e alçados ao status de dogma. Entender a deficiência como produto de uma sociedade altamente excludente e não mais como derivativa de providência divina ou falha biológica abre uma fenda, cuja consecução desencadeia uma nova perspectiva de compreensão do próprio gênero humano e da sociedade em questão. Tais elementos precisam ser pensados, apropriados e criticados pelos estudiosos da deficiência no Brasil, até como forma de ampliarmos o diálogo com outros recônditos, alargando, por conseguinte, nossa visão e imaginação sobre o fenômeno investigado. Esperamos ter contribuído para este processo.

\section{Referências}

ABBERLEY, P. The concept of oppression and the development of a social theory of disability. Disability Handicap and Society, v. 2, n.1, p. 5-19, 1987.

ASOCIACIÓN ESPANHOLA DE SOCIOLOGÍA DE LA DISCAPACIDAD (ASESDIS). Estatuto. Espanha, 2002. Disponível em: <http://www.asesdis.es/documentos/ ASESDIS_estatutos.pdf>

BARTON, L.; OLIVER, M. Disability studies, past, present and future. Leeds: Leeds University; The Disability, 1997. 
FINKELSTEIN, V. The disability movement has run out of steam. Disability Now, Febr. 1996.

GERALDI, D. Do estigma social à invisibilidade: a pessoa com deficiência física nas políticas públicas voltadas para a redução de desastres. 2010. Dissertação (Mestrado em Sociologia) - Programa de Pós-Graduação em Sociologia, Universidade Federal de São Carlos, São Carlos.

GIDDENS, A. Sociology. 6. ed. Cambridge, Mass: Polity, 2007.

GLEESON, B. Geographies of disability. London: Routledge, 1999.

MARX, K. O Capital: crítica da economia política. São Paulo: Nova Cultural, 1996. V. 1.

MARX, K.; ENGELS, F. A ideologia alemã. Trad. de José Carlos Bruni e Marco Aurélio Nogueira de Oliveira e Silva. 4. ed. São Paulo: Hucitec, 1984.

MORRIS, J. Impairment and disability: constructing an ethics of care which promotes human rights. Hypatia, Birminghan, v. 16, n. 4, p. 1-16, 2001.

OLIVER, M. The politics of disablement. Basingstoke: MacMillan, 1990.

OLIVER, M. Understanding disability: from theory to practice. Basingstoke: MacMillan, 1996.

SARTRE, J.P. Reflexões sobre o racismo. Trad. de J. Guinsburg. 6. ed. Rio de Janeiro: Difel, 1978.

STIKER, H.J. Corps infirmes et sociétés. Paris: Dunod, 2006.

UNION OF THE PHYSICALLY IMPAIRED AGAINST SEGREGATION (UPIAS). Fundamental principles of disability. London: UPIAS, 1976.

WILDE, O. A alma do homem sob o socialismo. Porto Alegre: L\&PM, 1996.

ZOLA, I.K. Toward the necessary universalizing of a disability policy. The Milbank Quarterly, New York, v. 67, sup. 2, pt. 2, p. 401-428, 1989.

Recebido em 30 de janeiro de 2012.

Aprovado em 19 de dezembro de 2012. 